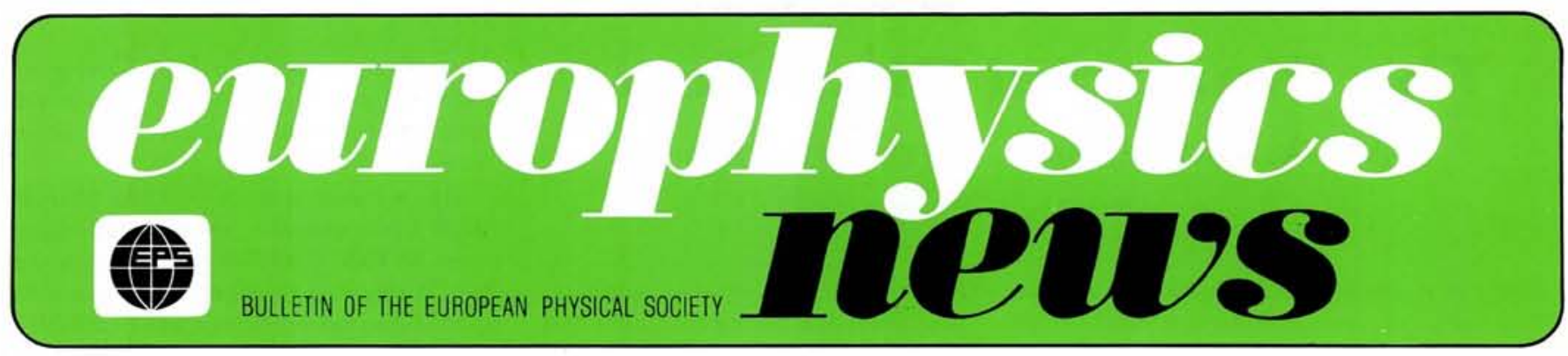

\title{
The President Reports
}

A summary of the report of the President, Professor R.A. Ricci that has been sent to the Group members, Associate Members and the delegates to Council of the IOMs, so that all delegates can consult with their colleagues before the Council meeting in Zagreb on 16/17 March 1989. IOMs wishing to comment should contact one of their delegates (see Europhys. News, June 1988).

The President opened his report by drawing attention to the problems of the XXI century for which EPS should be preparing itself. The Society had great potentiality, but was currently restricted in its scope by the limited number of individual members and the total financial envelope in which it had to work, see next page.

The main instruments through which EPS operates are the Advisory Committees, the Divisions and Interdivisional Groups.

\section{Advisory Committees}

The central preoccupation of the Advisory Committee on Applied Physics and Physics in Industry (ACAPPI) is the series of Europhysics Industrial Workshops that are organised in particular for the benefit of our industrial Associate Members. They bring together physicists from the universities and industry to discuss emerging techniques that have market significance. Three have so far been held and the next on lon Beams in Materials (see page 32) will take place in Bad Honnef in October.

Since EPS revised the scheme of Europhysics Journals to replace it by a procedure of Recognition for journals which meet certain criteria, 40 applications have been approved. The survey on word processors organised by the Publications Committee was supported by six publishers and resulted in some 1100 questionnaires being returned. On average about $80 \%$ of physics papers are prepared on word processors, the range of types and programmes being very wide. Expert analysis is being undertaken after which ways will be sought of introducing some harmonisation.

Applications for Approval or Sponsorship of events handled by the Conference Committee continue at a steady rate. Few problems arise if organisers have followed the guidelines. Consideration is being given to establishing a coordination office to assist in avoiding overlaps and too short a period between conferences of similar content.

The work of the Physics Education Committee is concentrated on organizing Study Conferences of restricted size and scope.
One was held in Smolenice on teacher education and one in Orsay on the use of history of physics for pedagogical purposes. The Group dealing with this which became a subset of the Committee is seeking to become an Interdivisional Group.

Within the framework of Physics and Society the East-West workshop on Nuclear Winters is being rounded off and plans have been laid for a follow up to be held in Torino in the Autumn with a study of Induced Critical Conditions in the Atmosphere.

\section{Divisions and Groups}

To a large extent the Divisions have over the past years given their attention to bring ing order into international conferences and placing them under the EPS umbrella (see Europhys. News Meetings Issues).

The Astronomy and Astrophysics Division, however, has also been concerned with the slow movement towards establishing a European Astronomical Society. On the Agenda for many years, the project was given substance at a meeting of Presidents of national European astronomical societies held at the General Assembly of the IAU in August 1988. Two European astronomers have been charged with the task of drawing up a constitution for a society based on individual members. This is to be ready for examination at the European Regional Astronomy Meeting to be held in Tenerife in July of this year.

A notable success of the High Energy and Particle Physics Division is to persuade the organisers of IUPAP's Conference on Lepton and Photon Interactions to join it and CERN in preparing the 1991 high energy physics conference in Geneva. At this year's (1989) biennial conference in Madrid in September, for the first time an EPS High Energy Physics Prize will be presented. Funding for this has come from capital provided by industry and HEPP Divisional resources.

A proposal has been received, following the successful accelerator conference held in Rome in June 1988 to establish an Interdivisional Group on Accelerators which Council will be invited to pronounce on.
The Board of the Quantum Electronics Division is well represented on the new International Council of Quantum Electronics. With the establishment of a biennial European conference (EQEC), the first of which took place in Hannover in September 1988, alternating with the international conference (IQEC) when in Europe, a reasonable balance has been brought into the QE conference scene.

\section{Interdivisional Groups}

The Group on Experimental Physics Control Systems has come a long way in the year. 24 laboratories are now actively participating and both Digital Equipment Corp. (Europe) and Hewlett-Packard have donated computer configurations. These will be used in the project for standardising controls protocols of power convertors. CERN has also given financial support to allow its technical board TEBOCO to take part in the Group's activities. In addition to this project the Group is active in instrumentation controls, and is studying an application soft ware kit, and real time software systems. Europhysics News will return to these projects in more detail at a later time.

The Physics for Development Group was encouraged by the workshop it held in Nairobi on materials science and solar energy. Collaborations have been set up to study the performance of special solar equipment in different climates, on photo voltaic cells and materials for passive cooling. A regional centre for testing and calibration is planned. The IGPD was also involved in a joint programme that has seen the first physicist from Bergen starting work in Dar es Salaam with a view to building up a sandwich M.Sc. programme. The first Southern European School of Physics lasting three weeks will be held in Istanbul in 1990. The subject will be the physics of novel semiconductor structures and devices.

The most important new initiative is to set up with UNESCO a European Advisory Committee on Energy Storage and Saving. Council will be invited to agree the terms of a formal agreement. 